\title{
MANAGEMENT OF FOURNIER'S GANGRENE IN A WOMAN AFTER EPISIOTOMY
}

\author{
I Kamoun, O Chaouch, S Taghouti, A Mbarki, A Ammous, A Cherif \\ Department of anesthesiology and intensive care - Rabta Hospital - Tunisia
}

\section{Background}

Fournier's gangrene is a fulminate form of infective necrotizing fasciitis usually affecting the perineum and the genitals (1). It is caused by a mixture of aerobic and anaerobic microorganisms. It commonly occurs in elderly men (2), but it can also affect women and children. This case illustrates the steps to follow to deal safely with this rare complication in a woman after episiotomy.

\section{Case report}

A 26-year-old woman was referred to our intensive care unit (ICU) with clinical signs of septic shock, two days after a childbirth. The presentation was a FG with a necrosis of the perineum's soft tissues. That was a complication of an episiotomy during the labor.

The initial resuscitation was done in the ICU with orotracheal intubation and physiologic monitoring. Vasopressors were introduced to improve hemodynamics. Moreover, an urgent surgical debridement of all necrotic tissue was done and high doses of broad spectrum intravenous antibiotic therapy were directed toward aerobic, anaerobic, and gram-positive and negative organisms.

The correction of hypovolemia, electrolyte imbalances and hyperglycemia were also taken into consideration. Secondly, colostomy has been used for fecal diversion because of severe perineal involvement. Hyperbaric oxygen therapy was done three times to improve the local results. Extubation was carried out carefully three weeks later. The young mom had got psychological and nutritional support and a plastic reconstruction is planned for her.

\section{Discussion}

Although rare, especially in women, FG remains a lifethreatening disease. The cornerstones of its treatment are intensive supportive care, urgent surgical debridement of all necrotic tissue as well as high doses of broadspectrum antibiotics. In fact, bacteriological tests are usually negative. The debridement is repeated until the cleaning of the cutaneous hurts.
Urgent resuscitation with fluids, blood transfusions and vasopressors may be needed in shocked patients. The rectal diversion decreases the number of germs in perineal region and improves wound healing. Hyperbaric oxygen therapy should be done when it is available to a better result.

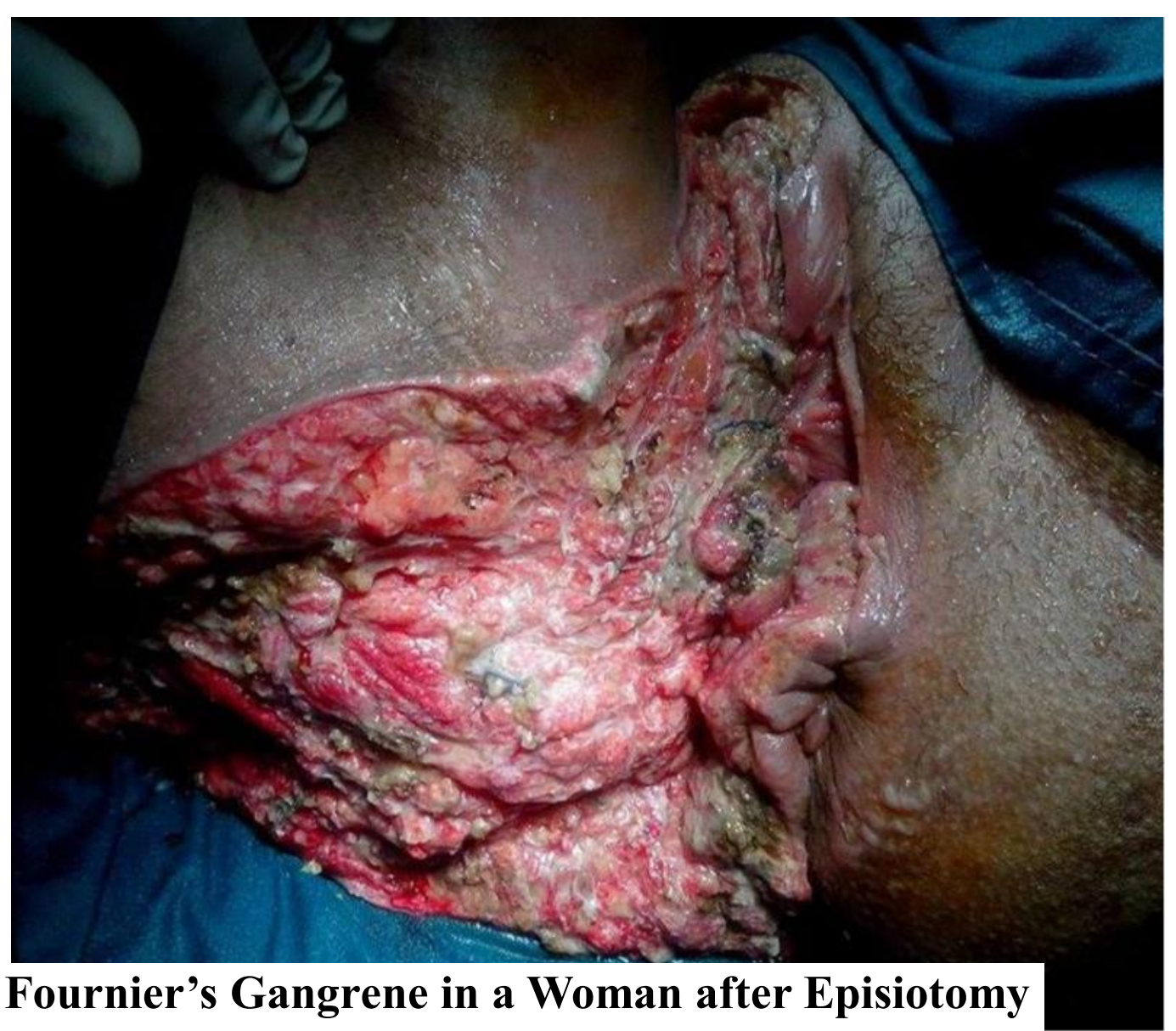

\section{Conclusion}

FG is a serious surgical emergency with a high mortality rate. Although it can be lethal, it is still a challenging situation in the field of surgical infections and needs special attention. Early diagnosis and treatment decrease its morbidity and mortality. Physicians should consider this disease in female patients and manage it methodically.

\section{References}

1. Gangrène de Fournier : prise en charge chirurgicale, Progrès FMC, 2014, 24, 3, F80-F85, A. Lipsker, F. Le Roux, F. Saint, G. Pignot

2. Management of Fournier's gangrene: case report and literature review, Acta Clin Croat 2010; 49:453-457, Josip Katušić, Goran Štimac. 